\title{
BIOASSAY EKSTRAK Selaginella willdenowii DENGAN BRINE SHRIMP LETHALITY TEST (BSLT)
}

\section{BIOASSAY EKSTRACT Selaginella willdenowii WITH BRINE SRIMP LETHALITY TEST (BSLT)}

\author{
Wida Witriani ${ }^{1}$, Endang L. Widiastuti ${ }^{1}$, M Kanedi $^{1}$, Nuning Nurcahyani ${ }^{1}$ \\ 1 Jurusan Biologi Fakultas MIPA Universitas Lampung \\ e-mail:wida_witriani@yahoo.co.id \\ Jurusan Biologi Fakultas MIPA Universitas Lampung \\ Jl. Soemantri Brojonegoro No.1, Bandar Lampung, Lampung, Indonesia, 35145
}

\begin{abstract}
Abstrak
Selaginella merupakan tumbuhan paku yang banyak tersebar di wilayah Indonesia salah satunya di wilayah Lampung. Selaginella memiliki banyak kegunaan diantaranya dapat digunakan sebagai bahan kerajinan tangan, ornamen dan sebagai obat tradisional. Potensi Selaginella yang dapat memberikan manfaat positif terutama sebagai obat tradisional belum banyak diketahui dan dioptimalkan penggunaanya oleh masyarakat. Penelitian untuk mengetahui pengaruh toksisitas telah dilakukan dengan Uji Brine Shrimp Lethality Test (BSLT). Ektraksi Selaginella diambil dengan cara maserasi menggunakan aquades kmudian disaring dan di keringkan hingga menjadi pasta. Pasta Selaginella di encerkan dan dibuat menjadi $0,2,4,6,8,10,12$, dan $20 \%$. Analisis data menggunakan varian satu arah (ANOVA) $(\alpha=0,05)$. Uji BSLT diterapkan pada 8 konsentrasi ekstrak Selaginella yang berbeda dengan 12 dan 24 jam pengamatan. Pada jam ke 12 konsentrasi $2 \%$ menunjukkan nilai mortalitas terendah sebesar $14,28 \%$ pada konsentrasi $20 \%$ mnunjukkan nilai tertinggi sebesar sebesar $26,78 \%$, kemudian pada jam ke 24 nilai mortalitas terendah adalah pada konsentrasi $2 \%$ sebesar $8,90 \%$ dan pada nilai tertinggi pada konsentrasi $20 \%$ yaitu sebesar $26,78 \%$. Ekstrak aquades Selaginella willdenowii bersifat toksik tetapi toksisitasnya rendah terhadap Artemia salina Leach juga tidak menunjukkan perbedaan yang nyata pada konsentrasi rendah.
\end{abstract}

Kata kunci: Selaginella wildenowii, Artemia salina, $L C_{50}$.

\begin{abstract}
Selaginella is one of ferns which widely distribute throughout Indonesia including Lampung region. Many uses can be made from Selaginella including handycraft, ornaments, as well traditional medicine. Yet, potential use of Selaginella as traditional medine has not been thoroughly explored especially for anticancer. In order to study its toxicity effect the study was conducted by undergone Brine Shrimp Lethality Test (BSLT). The aim of the study was to determine the lethal concentration of the Selaginella extract. Masseration by aquadest was applied for extraction of Selaginella followed by dehydration. The paste of Selaginella then was diluted and made into $0,2,4,6,8,10,12$, and $20 \%$. The BSLT then was applied to these 8 different concentration of Selaginella for 12 and 24 hours observation. ANOVA with a $5 \%$ was used to analyze the data. The result indicated that in 12 hours of observation the highest mortality $(26.78 \%$ ) was showed by $20 \%$ selaginella concentration and the lowest mortality (14.28\%) showed by $2 \%$ of Selaginella concentration. In 24 hours observation indicated that the highest mortality $(26.78 \%$ ) was showed by $20 \%$ of selaginella concentration and the lowest mortality $(8.90 \%)$ showed by $2 \%$ of Selaginella concentration. Selaginella willdenowii aquadest extract show any toxic but the low level toxicity on the Artemia salina as well it did not significantly different compare to those lower concentrations.
\end{abstract}

Key words : Selaginella wildenowii, Artemia salina, $L C_{50}$.

\section{PENDAHULUAN}

Selaginella merupakan salah satu tumbuhan paku yang dapat digunakan sebagai tanaman obat tradisional. Sellaginella adalah tumbuhan yang mengandung flavonoid yang merupakan antioksidan ampuh sebagai pencegah kanker dan juga memiliki efek antimikroba. Prinsip suatu tanaman dapat digunakan sebagai antikanker adalah apabila tanaman tersebut mengandung senyawa yang bersifat sitotoksik.

Yohana (2005), mengungkapkan bahwa pengobatan dengan obat tradisional secara u- 
mum dinilai lebih aman dibandingkan dengan pengobatan modern, karena efek samping yang ditimbulkan oleh obat tradisional lebih sedikit. Menurut Departemen Kesehatan (2002), obat tradisional tidak dapat dipisahkan dari kehidupan masyarakat Indonesia karena sudah menyatu dengan budaya bangsa serta banyak digunakan di berbagai lapisan masyarakat. Sesuai standar mutu WHO, obat tradisional harus memenuhi beberapa persyaratan meliputi kualitas, keamanan, dan khasiat.

Senyawa yang diduga memiliki khasiat obat seperti sebagai bahan anti kanker, harus diujikan terlebih dahulu pada hewan percobaan. Salah satu langkah awal pengujian adalah dengan menerapkan metode Brine Shrimp Lethality Test (BSLT), yaitu uji dengan menggunakan larva udang Artemia salina Leach (Meyer et al, 2010, Mc Laughlin dan Rogers, 2011, Carballo et al, 2005). Metode ini merupakan salah satu metode yang banyak digunakan untuk pencarian senyawa anti kanker baru yang berasal dari tanaman. Hasil uji toksisitas dengan metode ini telah terbukti memiliki korelasi dengan daya sitotoksis senyawa anti kanker (Rahman 2007). Selain itu, metode ini juga mudah dikerjakan, murah, cepat, dan cukup akurat. Bentuk ekstrak dipilih dengan harapan akan didapatkan kandungan senyawa aktif yang ada dalam Selaginella. Hasil penelitian ini diharapkan dapat dijadikan bahan informasi tentang potensi anti kanker pada Selaginella sebagai salah satu tanaman obat tradisonal.

\section{BAHAN dan METODE}

\section{Persiapan Tanaman Selaginella}

Sampel paku Selaginella diambil di sekitar sungai yang berada di sekitar Taman Hutan Raya Wan Abdul Rachman. Bagian tumbuhan Selaginella yang akan digunakan sebagai bahan aktif adalah seluruh bagian tanaman batang, daun, dan akar.

\section{Pembuatan Ekstrak Selaginella}

Bagian yang dibuat ekstrak merupakan keseluruhan dari bagian tumbuhan yaitu akar, batang dan daun Selaginella. Tumbuhan Selaginella dikeringkan di dalam oven dengan suhu 40-50 ${ }^{\circ} \mathrm{C}$ selama 5x24 jam sampai benar-benar kering. Selaginella yang telah kering dipotong-potong lalu dihaluskan dengan blender kering. Setelah itu direndam (maserasi) menggunakan aquades selama 24 jam kemudian disaring, langkah ini diulang sebanyak 3 kali untuk menghasilkan ekstrak cair Selaginella. Ekstrak Selaginella dihomogenkan dengan cara digoyang menggunakan shaker selama 24 jam pada kecepatan rendah agar ekstrak benar-benar homogen, kemudian diuapkan di dalam oven dengan suhu

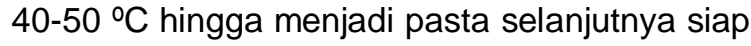
digunakan sebagai larutan stok.

\section{Persiapan Tempat Penetasan Hewan Uji}

Tempat untuk menetaskan Artemia dirancang menggunakan botol berukuran 1,5 I, dibagi menjadi dua bagian kemudian bagian atas botol dimasukkan ke dalam badan botol. Bagian tengah botol di lubangi dan diberi selang penghubung pada botol lainnya untuk tempat jalannya Artemia yang telah menetas.

\section{Penetasan hewan Uji Arthemia}

dilakukan dengan cara merendam kista dalam bentuk kering di dalam air laut yang diinkubasi dengan menggunakan sinar lampu TL hingga menetas menjadi larva nauplius. Larva nauplius selanjutnya dipisahkan dalam wadah baru, larva yang dapat digunakan sebagai hewan uji adalah larva yang telah berumur 48 jam.

\section{Tempat perlakuan}

Tempat yang digunakan untuk perlakuan pada penelitian ini adalah plate tetes yang terbuat dari porselin. Satu plate tetes memiliki cekungan sebanyak 16 cekungan dengan kedalaman $4 \mathrm{~cm}$. Cekungan ini yang akan diisi Artemia sebanyak 14 ekor dan diberi ekstrak Selaginella.

\section{Persentase pemberian ekstrak}

Penelitian ini menggunakan rancangan acak Lengkap (RAK) dengan 8 perlakuan dan masing-masing perlakuan diulang sebanyak 4 kali. Setiap perlakuan menggunakan Artemia sebanyak 14 ekor untuk melihat berapa banyak Artemia yang mati sebagai respon toksik tanaman Selaginella. Perlakuan tersebut adalah

1. 14 Artemia sebagai kontrol tanpa pemberian ekstrak.

2. 14 Artemia diberi ekstrak Selaginella sebanyak $2 \%$

3. 14 Artemia diberi ekstrak Selaginella sebanyak $4 \%$

4. 14 Artemia diberi ekstrak selaginella sebanyak $6 \%$

5. 14 Artemia diberi ekstrak Selaginella sebanyak $8 \%$

6. 14 Artemia diberi ekstrak Selaginella sebanyak $10 \%$

7. 14 Artemia diberi ekstrak Selaginella sebanyak $12 \%$.

8. 14 Artemia diberi ekstrak Selaginella sebanyak $20 \%$

\section{Parameter yang diamati}

Parameter penelitian yang digunakan adalah angka mortalitas larva Artemia, angka mortalitas dihitung dengan $\mathrm{LC}_{50}$ dengan memasukkan nilai probit (50\% kematian). Angka mortalitas larva dihitung dengan rumus berikut :

Angka mortalitas Larva $=$ (akumulasi mati/jumlah akumulasi hidup dan mati) x 100\% 
Angka probit dicari dengan menggunakan persamaan garis $\mathbf{y}=\mathbf{a}+\mathbf{b}_{\mathbf{x}}$

$$
\text { Keterangan: } \begin{aligned}
\mathrm{y} & =\text { log konsentrasi } \\
\mathrm{x} & =\text { Angka probit }
\end{aligned}
$$

\section{Analisis Data}

Data yang diperoleh berupa data kematian $\mathrm{Ar}$ temia yang dianalisis menggunakan varian satu arah (ANOVA) dengan $\alpha=5 \%$, untuk mengetahui adanya perbedaan yang signifikan antar kelompok perlakuan

\section{HASIL DAN PEMBAHASAN}

\section{Nilai Mortalitas Arthemia Salina Leach}

Hasil uji mortalitas larva Artemia salina Leach yang telah diberikan perlakuan ekstrak Selaginella wildenowii dengan berbagai konsentrasi disajikan pada Tabel 1 berikut :

Tabel 1. Rerata mortalitas larva Arthemia salina Leach yang telah diberi ekstrak Selaginella wildenowii pada 12 jam inkubasi

\begin{tabular}{cccc}
\hline No. & Konsentrasi & $\begin{array}{c}\text { X } \pm \text { SEM } \\
\text { (individu) }\end{array}$ & $\begin{array}{c}\text { Nilai Mortalitas } \\
(\%)\end{array}$ \\
\hline 1 & $0 \%$ & $0,14 \pm 0,028$ & 14,28 \\
2 & $2 \%$ & $0,19 \pm 0,033$ & 19,64 \\
3 & $4 \%$ & $0,21 \pm 0,059$ & 21,43 \\
4 & $6 \%$ & $0,21 \pm 0,028$ & 21,43 \\
5 & $8 \%$ & $0,23 \pm 0,017$ & 23,21 \\
6 & $10 \%$ & $0,23 \pm 0,033$ & 23,21 \\
7 & $12 \%$ & $0,24 \pm 0,020$ & 25,00 \\
8 & $20 \%$ & $0,26 \pm 0,017$ & 26,78 \\
Keterangan : X \pm SEM merupakan nilai rerata mortalitas \\
\multicolumn{4}{c}{ Arthemia salina L \pm galat dalam \% }
\end{tabular}

Nilai mortalitas Artemia berkisar antara 14,28$26,68 \%$ pada Tabel 1. menunjukan bahwa nilai mortalitas Arthemia yang diberi ekstrak Selaginella willdenowii dengan konsentrasi yang berbeda $(0 \%, 2 \%, 4 \%, 6 \%, 8 \%, 10 \%, 12 \%$ dan $20 \%$ ) tidak menunjukan adanya perbedaan yang nyata pada $\alpha=0,05$.

Pada 12 jam pengamatan semakin tinggi konsentrasi ekstrak yang diberikan maka semakin tinggi tingkat toksisitasnya terhadap Arthemia. Sesuai dengan teori Harborne (1994) yang menyatakan bahwa semakin tinggi konsentrasi ekstrak maka akan semakin tinggi sifat toksiknya, sehingga dapat membunuh Arthemia. Untuk lebih lanjut dilakukan uji dengan inkubasi selama 24 jam, data hasil penelitian terlihat pada Tabel 2.

Tabel 2 menunjukkan waktu inkibasi 24 jam menunjukan bahwa nilai mortalitas Arthemia yang diberi ekstrak Selaginella willdenowii dengan konsentrasi yang berbeda $(0 \%, 2 \%, 4 \%$,
$6 \%, 8 \%, 10 \%, 12 \%$ dan $20 \%)$ tidak menujukan adanya perbedaan yang nyata $(\alpha=0,05)$.

Tabel 2. Rerata mortalitas larva Arthemia Salina Leach yang telah diberi ekstrak Selaginella willdenowii pada 24 jam

\begin{tabular}{cccc}
\hline No. & Konsentrasi & $\begin{array}{c}\mathrm{X} \pm \text { SEM } \\
\text { (individu) }\end{array}$ & $\begin{array}{c}\text { Nilai Mortalitas } \\
(\%)\end{array}$ \\
\hline 1 & $0 \%$ & $0,08 \pm 0,017$ & 8,90 \\
2 & $2 \%$ & $0,16 \pm 0,059$ & 16,07 \\
3 & $4 \%$ & $0,23 \pm 0,033$ & 23,21 \\
4 & $6 \%$ & $0,23 \pm 0,033$ & 23,21 \\
5 & $8 \%$ & $0,23 \pm 0,033$ & 23,21 \\
6 & $10 \%$ & $0,24 \pm 0,067$ & 25,00 \\
7 & $12 \%$ & $0,24 \pm 0,020$ & 25,00 \\
8 & $20 \%$ & $0.26 \pm 017$ & 26,78 \\
\hline Keterangan : X \pm SEM merupakan nilai rerata mortalitas \\
\multicolumn{4}{c}{ Arthemia salina L \pm galat dalam \% }
\end{tabular}

Hal yang sama juga ditunjukan pada inkubasi 24 jam, yaitu semakin tinggi konsentrasi yang digunakan semakin tinggi tingkat toksisitasnya. Harmita dan Radji (2008) menyatakan bahwa ekstrak Selaginella wildonevii dikatagorikan sebagai tumbuhan yang cukup toksik. Efek toksik diduga karena kandungan bahan bioaktif yang terkandung di dalam ekstrak Selaginella, di antaranya saponin dan alkaloid. Hasil uji fitokimia menunjukkan bahwa ekstrak Selaginella willdenovii memiliki kandungan saponin yang lebih banyak dibandingkan ekstrak Selaginella plana dan Selaginella ornata (Chikmawati et al. 2009) Bahan bioaktif lainnya yaitu alkaloid yang mempunyai rasa pahit dan berfungsi sebagai anti serangga yang diduga juga dapat mempengaruhi efek toksik (Zuhud et al. 2006).

Disamping mortalitas, Artemia yang mati dalam vial percobaan karena perlakuan, mengalami disorientasi gerak (gerakannya tidak teratur). Artemia dalam vial ini tetap aktif bergerak, akan tetapi gerakannya berputar-putar pada satu titik kemudian mati.

Hubungan konsentrasi ekstrak Selaginella willdenowii dengan mortalitas Arthemia salina Leach dapat dilihat pada Gambar 1 berikut :

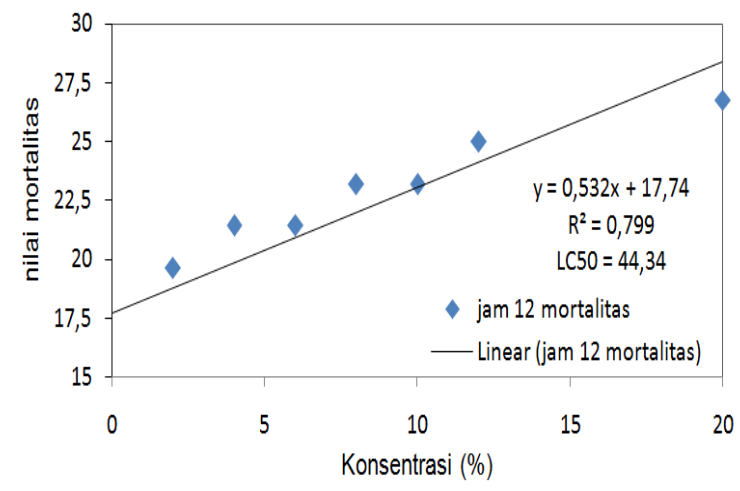

Gambar 1. Pemberian ekstrak $S$. willdenowii dengan persentase kematian Artemia pada 12 jam 
Pada Gambar 1 terlihat hubungan antara persentase kematian Arthemia salina yang diberi perlakuan ekstrak Selaginella willdenowii menunjukkan persamaan regresi linear adalah $\mathrm{y}=$ $0,532 x+17,74$, dengan nilai regresi sebesar 7,99 . Walau tidak menunjukan perbedaan yang nyata antar konsentrasi yang berbeda ekstrak Selaginella willdenowii menunjukan adanya peningkatan kematian dengan adanya peningkatan konsentrasi yang dibuat, yaitu dengan $r=$ 7,99 . Untuk lebih lanjut inkubasi dilakukan pada 24 jam pengamatan menunjukan hubungan yang serupa dengan nilai regresi 0,608.

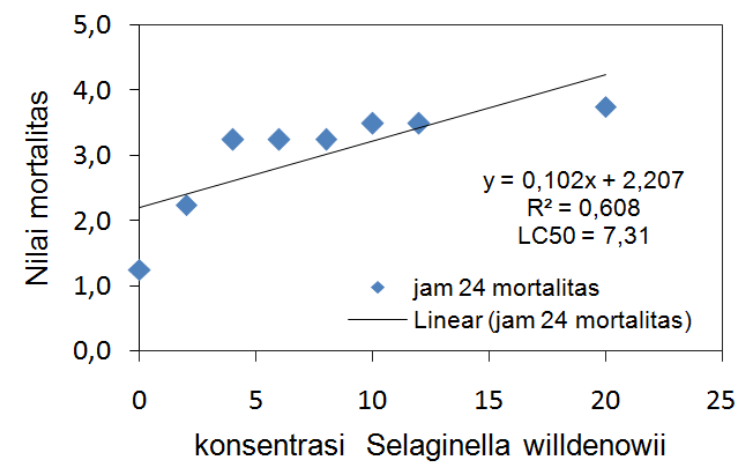

Gambar 2. Pemberian ekstrak Selaginella willdenowii dengan persentase kematian Arthemia pada 24 jam.

Pada Gambar 2 terlihat hubungan antara persentase kematian Arthemia salina yang diberi perlakuan ekstrak Selaginella willdenowii selama 24 jam pengamatan. Persamaan regresi linear menunjukkan persamaan $\mathrm{y}=0,731 \mathrm{x}+$ 15,75 .

Semakin tinggi konsentrasi yang dipakai juga menunjukan tingkat kematian yang tinggi. Namun seperti halnya pada pengamatan 12 jam ekstrak Selaginella willdenowii belum menunjukan tingkat toksik seperti yang disarankan oleh Meyer et al. Menurut Meyer et al. (1982), ekstrak tanaman dikatakan toksik jika memiliki LC $_{50}<1000 \mu \mathrm{g} / \mathrm{ml}$. melalui uji BSLT toksisitas tidak terlihat pada penelitian ini, diduga senyawa toksik yang dikandung oleh Selaginella willdenowii hanyan sedikit yang didapat dari proses ekstraksi karena Selaginella willdenowii diekstraksi menggunakan aquades, dengan cara simplisia Selaginella willdenowii direndam dengan aquades tanpa dididihkan. Dengan demikian biflavonoid yang terkandung di dalam Selaginella willdenowii tidak terekstrak dengan baik. Setyawan dan Darusman (2008) mengungkapkan bahwa pelarut dan cara isolasi yang digunakan untuk mengekstraksi Selaginella sangat mempengaruhi keragaman struktur kimia yang diperoleh. Keragaman struktur kimia biflavonoid ini sangat mempengaruhi bioaktivitas ekstrak tersebut.

\section{KESIMPULAN}

Berdasarkan penelitian yang telah dilakukan dapat disimpulkan bahwa pemberian ekstrak Selaginella terhadap Arthemia salina Leach pada jam ke 12 dan 24 menujukan nilai mortalitas tertinggi sebesar $26,78 \%$.

\section{DAFTAR PUSTAKA}

Chikmawati T, Wijayanto A, Miftahudin. 2009. Potensi Selaginella Sebagai Antiok-sidan. Seminar Nasional Biologi XX: Universitas Islam Negeri Malang.

Harborne, J. B. 1994. The Flavonoids. Chapman and Hall. London.

Meyer, B. N., Ferrigni, N. R., Putman, J. E., Jacbsen, L. B., Nicols, D. E., and McLaughlin, J. L. 1982. Brine Shrimp : A Comvenient general Bioassay For Active Plant Constituents. Plant Medica.

Rahman M, Rias M, Desai UR. 2007. Synthesis of biologically relevan biflavonoid. Reviev. Chemistri and Biodiversity 4: 2495-2527.

Scheuer, J. S. 1994. Produk Alami Lautan. Cetakan pertama. IKIP Semarang Press. Semarang.

Setyawan, A.D dan Darusman, L.k. 2008. Senyawa Biflavonoid pada Selaginella Pal. Beauv. dan Pemanfaatannya. B I O D I V E R S I T A S ISSN: 1412-033X Volume 9, Nomor 1 Januari 2008 Halaman: 64-81. Bogor. Departemen Kimia, FMIPA, Institut Pertanian Bogor (IPB).

Setyawan, A.D. 2011. Natural products from Genus Selaginella (Selaginellaceae). Nusantara Bioscience 3: 44-58.

Yohana, A. Y. 2005. Khasiat Tanaman Obat. Pustaka Buku Murah. Jakarta.

Zuhud EAM, Ekarelawan, Riswan S. 1994. Indonesian tropical forests as a source of medicinal plant genetic diversity. In: Zuhud EAM, Hary (ed). 2006. Preservation of the utilization of medicinal plant diversity of Indonesian tropical forests. Faculty of Forestry IPB-LATIN. Bogor. 